Available online on 15.03.2020 at http://jddtonline.info
Open Access to Pharmaceutical and Medical Research
unrestricted non-commercial use, provided the original work is properly cited

Open@ Access

Review Article

\title{
A Review on Nigella sativa: A Marvel Herb
}

\author{
Safiya Begum* and Dr. Abdul Mannan \\ Department of pharmaceutics, Deccan School of Pharmacy, Dar-us-salam, Aghapura, Hyderabad, telangana-500001
}

\begin{abstract}
Nigella sativa (N. sativa) (Family Ranunculaceae) is a widely used medicinal plant throughout the world. It is very popular in various traditional systems of medicine like Unani and Tibb, Ayurveda and Siddha. Seeds and oil have a long history of folklore usage in various systems of medicines and food. The seeds of $N$. sativa have been widely used in the treatment of different diseases and ailments. In Islamic literature, it is considered as one of the greatest forms of healing medicine. It has been recommended for using on regular basis in Tibb-e-Nabwi (Prophetic Medicine). Nigella sativa and its constitutions including some isolated compounds are the potential sources of remedies of varieties of ailments such as antioxidant, anti-inflammatory, antibacterial, antifungal, antiparasitic and antiprotozoal, antiviral, cytotoxic, a nticancer, neuro-, gastro-, cardio-, hetapto- and nephroprotective activities. In addition, the N. sativa implies beneficiary effects on reproductive, pulmonary and immune systems along with diabetes mellitus (DM), fertility, breast cancer, dermatological complications, dehydration, dyspepsia, osmotic balance and so on. Among the other isolated chemical moieties, thymoquinone (TQ) is a good target for its potential antimicrobial, antimicrobial, antiinflammatory, chemopreventive, antitumoral and other activities. $N$. sativa has got the place among the top ranked evidence based herbal medicines. This is also revealed that most of the therapeutic properties of this plant are due to the presence of thymoquinone which is major bioactive component of the essential oil. The present review is an effort to provide a detailed survey of the literature on scientific researches of pharmacognostical characteristics, chemical composition and pharmacological activities of the seeds of this plant.
\end{abstract}

Keywords: Nigella sativa, Miracle herb, Ranunculaceae, Habat-ul-Sauda, Thymoquinone, Tibb-e-Nabwi, Black seeds, Anti-diabetic, Antioxidant

Article Info: Received 10 Jan 2020; Review Completed 12 Feb 2020; $\quad$ Accepted 21 Feb 2020; Available online 15 March 2020

\section{Cite this article as:}

Begum S, Mannan A, A Review on Nigella sativa: A Marvel Herb, Journal of Drug Delivery and Therapeutics. 2020; 10(2):213-219 http://dx.doi.org/10.22270/jddt.v10i2.3913

*Address for Correspondence:

Safiya Begum, Department of pharmaceutics, Deccan School of Pharmacy, Dar-us-salam, Aghapura, Hyderabad, telangana-

500001

\section{INTRODUCTION:}

For many centuries, medicinal plants have been used in various indigenous medicinal systems as well as folk medicines to cure diseases. In addition, medicinal plants are also used in herbal medicine preparation as they are considered safe compared to modern allopathic medicines. Since only a few plant species have been thoroughly investig ated for their medicinal properties,

potential, mechanism of action, safety assessment and toxicol ogical studies, many researchers focus on medicinal plants.

Nigella sativa (N. sativa) (Family Ranunculaceae) is emerging as a miracle herb with a rich historical and religious background among various medicinal plants as many research has revealed its wide range of pharmacological potential. N. Sativa is widely referred to as black seed. N. Sativa is native to Southern Europe, North Africa and Southwest Asia and is grown in many countries around the world, including the Middle East Mediterranean region, Southern Europe, India, Pakistan, Syria, Turkey and Saudi Arabia.[1]
The N. sativa seeds and oil have been widely used in the treat ment of various diseases worldwide for centuries and it is an important drug in the traditional Indian medicine system suc $\mathrm{h}$ as Unani and Ayurveda.[2],[3]Among Muslims, because it was mentioned that black seed is the remedy for all diseases except death in one of the prophetic hadith, it is considered one of the greatest forms of healing medicine available. Tibbe-Nabwi (Prophetic Medicine) is also recommended for regular use. ${ }^{[4]}$

Nigella sativa is an annual flowering plant.It grows to a height of $20-30 \mathrm{~cm}$ (7.9-11.8 inches) with linear lanceolate leaves. The delicate flowers have $5-10$ petals and usually yellow, white, pink, pale blue or pale violet colors. The plant fruit is a large and inflated capsule consisting of $3-7$ united follicles with numerous seeds each of them. The black colored seeds are flattened, oblong and angular, with $0.2 \mathrm{~cm}$ long and $0.1 \mathrm{~cm}$ wide funnel shapes. [3]

N. Sativa has been extensively studied for its biological and therapeutic activities and has been shown to have a wide range of activities such as diuretic, antihypertensive, 
antidiabetic, immunomodulatory, analgesic, antimicrobial, anthelmintic, analgesic, anti-inflammatory, spasmolytic, bronchodilator, gastroprotective, hepatoprotective, renal and antioxidant. The N. Sativa seeds are widely used to treat diseases such as bronchitis, asthma, diarrhea, rheumatism and skin disorders. It is also used as a liver tonic, digestive, anti-diarrheal, appetite stimulant, emmenagogue, to increase the production of milk in nursing mothers to combat parasite infections and to support the immune system.[5],[3]Most of this plant's therapeutic properties are due to the presence of thymoquinone (TQ), which is an major active chemical component of essential oil's . Black seeds are also used in foods such as aromatic additives in breads and pickles because there toxicity is very low.[6]

Nigella sativa seeds have wide therapeutic effects and have been reported to have significant effects on many ailments such as skin diseases, jaundice, gastrointestinal problems, anorexia, conjunctivitis, dyspepsia, rheumatism, diabetes, hypertension, intrinsic hemorrhage, paralysis, amenorrhea, anorexia, asthma, cough, bronchitis, headache, fever, influenza and eczema. Thymoquinone (TQ) has various beneficial properties and is one of the most active constituents. Focus on the effects of antimicrobials, various extracts of N. sativa extracts and TQ have a wide range of antimicrobials including gram-negative, gram-positive bacteria, viruses, parasites, schistosomes and fungi. The efficacy of N. Sativa seeds and TQ are variable and depend on target species. The present review paper attempts to describe all antimicrobial activities performed by different researchers.

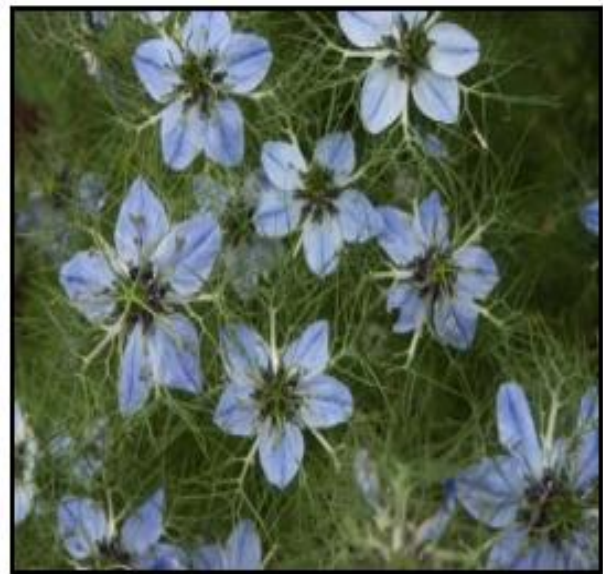

Fig no.1: N.sativa flowers

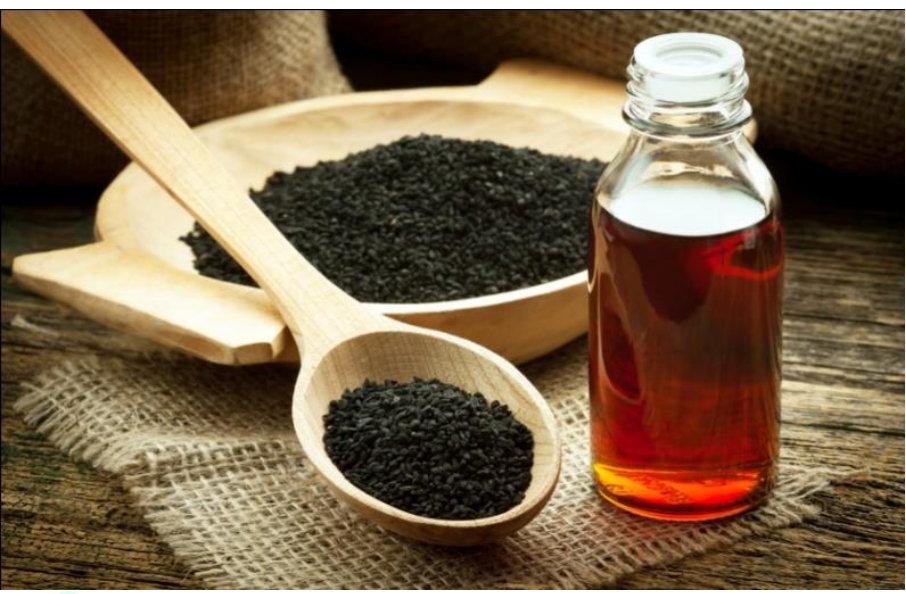

Fig no.2: N.sativa seeds and oil

\section{TAXONOMIC CLASSIFICATION:[7]}

- Kingdom

: Plantae

- Subkingdom

: Tracheobionta

- $\quad$ Super division

: Spermatophyta

- Phylum

- Class

- $\quad$ Order

- Family

: Magnoliophyta

: Magnoliopsida

: Ranunculales

- Genus

: Ranunculaceae

- $\quad$ Species

: Nigella

: Sativa

\section{COMMON NAMES:}

- Black cumin, Fennel flower, Nutmeg flower, Black seeds, Black caraway, Roman coriander, Damascene, Devil in the bush, Wild onion seeds etc.

\section{SYNONYMS:}

- English : Fennel flower Black cumins, Love-in-amist., nutmeg flower, Roman coriander

- Arabic : Habatut Barakah Shooneez, Habba Sauda, Habb al-barka

- $\quad$ Sankrit : Krishana - Jiraka, Upakunchika

- German : Schwarzkümmel

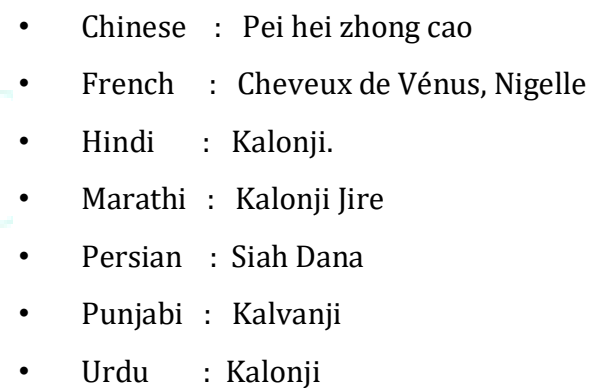

All though above are common synonyms referred, there is indeed a lot of confusion about the name of Nigella sativa seed. N.sativa seed is called black cumin, black caraway and black onion seed in many regions such as Central Asia and Northern India, but there is no botanical relationship between Nigella sativa seed and any such seed. Many time these resembling seed are often part of the stock that is commercially available and used as adulterants.

\section{CULTIVATION AND COLLECTION:[8]}

- Nigella sativa is an annual herb mostly grown during the winter season. It is grown on light and heavy soil. The sowing period is between October and November and the harvest is between April and May. Its yield is about $300 \mathrm{~kg}$ per acre to $400 \mathrm{~kg}$ per acre.

- Sowing seeds as germination in the upper soil will delay if sown deep inside. It need not be irrigated frequently. When the fruit / capsule turns yellowish, the crop is harvested. It 
can be threshed by trampling with a tractor or proper thresher after harvesting and proper drying. The seeds are stored properly in bags or containers after threshing.

\section{CHEMICAL COMPOSITION OF NIGELLA SATIVA:}

Many active compounds in various black seed varieties have been isolated, identified and reported so far. The most important active compounds are thymoquinone (30\% $48 \%)$, thymohydroquinone, dithymoquinone, p-cymene $(7 \%$ $-15 \%)$, carvacrol $(6 \%-12 \%)$, 4-terpineol $(2 \%-7 \%)$, tanethol ( $1 \%-4 \%)$, longifolene $(1 \%-8 \%), \alpha$-pinene and thymol, etc. Black seeds also contain trace amounts of some other compounds. Seeds contain two different types of alkaloids, i.e. isoquinolin alkaloids, e.g. nigellicimine and nigellicimine $\mathrm{N}$ - oxide, and alkaloids containing nigellidine and nigellicine, pyrazol alkaloids or indazole ring alkaloids. In addition, N. Sativa seeds also contain alpha - hederin, a water - soluble pentacyclic triterpene and saponin, a potential anticancer agent.[9,10]

Some other compounds have also been found in trace amounts, e.g. carvone, limonene, citronellol. Most of N.sativa pharmacologic properties is primarily attributed to quinine components, of which TQ is the most abundant. TQ yields dithymoquinone and higher products for oligocondensation on storage. The N. Sativa seeds contain protein $(26.7 \%)$, fat (28.5\%), carbohydrates (24.9\%), crude (8.4\%) and total ash $(4.8 \%)$. The seeds also contain good quantities of different vitamins and minerals such as $\mathrm{Cu}, \mathrm{P}, \mathrm{Zn}$ and Fe etc. The seeds contain carotene that is converted to vitamin A through the liver. Vanillic acid is reported in the root and shoot.[9,11]

\section{PHARMACOLOGICAL ACTIVITIES:}

\section{Antibacterial Effect:}

Antibacterial effect of nigella sativa seeds was studies using the filter paper disc method. The concentration-dependent inhibition of Gram-positive bacteria represented by Staphylococcus aureus was caused by filter paper disks impregnated with the diethyl ether extract of Nigella sativa seeds (25-400 microgram extract / disk). Pseudomonas aeruginosa and Escherichia coli (but not Salmonella typhimurium) and a pathogenic yeast Candida albicans represent gram - negative bacteria. The extract of nigella sativa showed antibacterial synergism with streptomycin and gentamicin and showed additive antibacterial action with the combination of spectinomycin, erythromycin, tobramycin, doxycycline, chloramphenicol, nalidixic acid, ampicillin, lincomycin and sulphamethoxyzole trimethoprim. When injected at the infection site, the extract successfully eradicated a non - fatal subcutaneous staphylococcal infection in mice.[12]

\section{Antiviral Effect:}

N. Sativa has been found to increase helper T - cell (T4) and $\mathrm{T}$ - cell (T8) suppressor ratio and the natural killer (NK) cell activity of healthy volunteers (El - Kadi and Kandil, 1986). In addition to improving immunity, N.sativa extract had some inhibitory effect on human immune deficiency virus protease,but it did not identify the active principle(s) responsible for this activity (Ma et al., 1994). Moreover, N. Sativa oil was undetectable in the liver and spleen when administered intraperitoneally to mice infected with murine cytomegalovirus for 10 days, while it was still detectable in the control mice. This action was considered to be associated with increasing the number and function of $\mathrm{M}$ - phi and CD4+ve $\mathrm{T}$ cells and increased INF - gamma production (Salem and Hossain, 2000).

\section{Antifungal Effect:}

The comparative antimicrobial activity of tannins, saponins, alkaloids, essential oil, brown and yellow crystals separated from essential oil and thymoquinone, was evaluated, against a yeast (Saccharomyces cerevisiae), two molds (Penicillium notatum and Aspergillus niger), two Gram-positive bacteria (Staphylococcus aureus and Bacillus subtilis), five Gramnegative bacteria (Escherichia coli, Klebsiella pneumoniae, Pseudomonas aeruginosa, Salmonella typhimurium and Shigella flexneri) and an acid-fast bacterium (Mycobacterium phlei). Essential oil, its fractions and thymoquinone were the most active constituents against the tested microorganisms followed by alkaloids and saponins, respectively. On the contrary, tannins of N. sativa did not have any activity against all tested microorganisms. The tested Gram-positive bacteria were significantly $(\mathrm{p}<0.0001)$ more sensitive than Gram-negative bacteria and Sac. cerevisiae was more sensitive than $P$. notatum and A. niger ( $p<0.001$ ) for the tested constituents. Concentrations as low as $4-16 \mu \mathrm{g} / \mathrm{ml}$ of the volatile oil or its fractions killed $\mathrm{S}$. aureus and B. subtilis. The tested MICs and MBCs N.Sativa components against Gram - positive and Gram - negative bacteria in Muller - Hinton were 2 to 8 times higher than their minimal M9 values, suggesting an interaction between the components tested and the organic components.[13]

\section{Hair Loss:}

In the book Natural Remedies of Arabia, Robert W. Lebling and Donna Pepperdine MH[14] referred to the use of Nigella sativa seed powder together with Arugula juice, Olive oil, Vinegar in Saudi Arabia for hair loss control.[15]

Telogen effluvium is a condition in which hair thinning or shedding occurs in the telogen phase due to early hair entry. In the Nigella sativa seed study, which has Thymoquinone (TQ) as a primary active and has anti-oxidant and antiinflammatory effects by inhibiting pro-inflammatory mediators, such as cyclooxygenase and prostaglandin D2 was used. 20 patients affected by Telogen effluvium were selected for the double-blind, placebo-controlled and randomized study. 10 of these patients were treated with a $0.5 \%$ Nigella sativa lotion on a daily basis for three months, while the other 10 patients were treated with placebo on a daily basis for three months.Improvement assessment was performed using video dermatoscopic analysis (Trichoscan

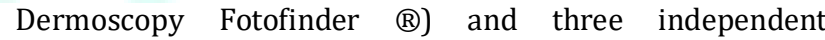
dermatologists were examined before treatment (T0), three months after treatment (T3) and six months after treatment (T6).

Significant improvement was observed in 70 percent of Nigella Sativa-treated patients. Videodermatoscopic analysis showed a significant increase in hair density and hair thickness in patients treated with Nigella sativa. It was also observed that in most patients with Telogen effluvium, Nigella sativa reduced inflammation.[16]

In a clinical study, hair oil containing Kala Jera oil (Nigella sa tiva), Narkal oil (Cocos nucifera), Amloki (Emblica officinalis), Henna (Lawsonia alba), Durba Ghas (Cynodon dactylon), Mathi (Trigonella foenumgraecum) were studied in 90 patients for their hair loss control activity. It was found that hair falls reduced to $76 \%, 72 \%, 67 \%, 59 \%$, $32 \%, 0 \%$ on 15 days, 30 days, 45 days, 60 days, 75 days and 90 days by using this experimental herbal hair oil over purified coconut oil.[17]

\section{Antioxidant Properties:}

Antioxidant properties of food, herbal and dietary suppleme nts play a critical role in the prevention of degenerative 
diseases mainly cancer, cardiovascular and neurodegenerative diseases.The polyphenolic compound concentr ation is directly proportional to the antioxidant properties of food, herbal and dietary supplements.

In a study where essential Nigella sativa seed oil was tested $\mathrm{f}$ or potential antioxidant activity using two TLC screening me thods, it was shown that thymoquinone, carvacrol, t anethole and4terpineol showed respectable radical scavenging prope rties.When tested for a non specific hydrogen atom or electr on donating activity in the diphenyl picrylhydrazyl assay, the se four constituents and the essential oil had variable antioxi dant activity.They were also effective as radical hydroxyl sca vengers in the liposome non enzymatic lipid peroxidation te st and deoxyribose degradation test.[18]

\section{Preservative Property:}

Due to various Nigella sativa seed antimicrobial activity, it was assessed for its natural preservative property where Jordanian Nigella sativa seed was used as a preservative for safe storage of date pastes. In experiments, 100, 200, and $400 \mathrm{ppm}$ of Jordanian Nigella sativa adequately controlled the post - processing development of contaminating microorganisms present in stored date pastes.During four months of storage at room temperature, $400 \mathrm{ppm}$ was found to preserve dates, color, flavor, texture, and taste attributes of sensory quality. This was comparable to the preservatives of 400 ppm of sodium benzoate. [19]

The effect of Nigella sativa seed $(1 \%$ and $3 \%)$ and oil $(0.3 \%$ and $1 \%$ ) was studied in soft white cheese (prepared from raw ewe's milk and pasteurized ewe's milk from the laboratory) on some food poisoning, pathogenic bacteria and total bacterial count (CFU/g).

The soft white cheese was inoculated at a concentration of about $1 \times 106 \mathrm{CFU} / \mathrm{ml}$ with Staphylococcus aureus, Brucella melitensis and Escherichia coli. At 0th, 2nd, 4th and 6th days of refrigerator storage, cheese samples were checked for the bacterial count.

Results showed a significant decrease in total bacterial counts $(\mathrm{P}<0.05)$, Staphylococcus aureus, Brucella melitensis and Escherichia coli counts in cheese samples treated with Nigella sativa seed $(1 \%$ and $3 \%)$ and oil $(0.3 \%$ and $1 \%)$ with pronounced concentration-dependent inhibition. In contrast, cheese samples which exerted a significant increase in bacterial counts as they reached $2.8 \times 10^{7}, 2.95 \times 10^{6}$, $2.22 \times 10^{6}$ and $2.885 \times 10^{6} \mathrm{CFU} / \mathrm{g}$ for the total bacterial counts, Staphylococcus aureus, Brucella melitensis and Escherichia coli at the 6th day of refrigerator temperature storage respectively. Nigella sativa seed oil $(0.3 \%$ and $1 \%)$ was significantly more effective $(\mathrm{P}<0.05)$ than seed $(1 \%$ and $3 \%)$ as an antibacterial agent.[20]

\section{Sun Protection:}

In a study, cream was tested for in vitro sun protection factor with $0.5 \%$ Nigella sativa oil. It has been observed that the $0.5 \%$ Nigella sativa oil formulation has a SPF value of 1.05 with an ultra-boot star rating of 2 . Rating of 2 is considered to have a real sunscreen activity.[21]

\section{Wound Healing:}

Nigella Sativa seed and oil were found in farm animals to promote wound healing (Ahmed et al., 1995). In addition, ether extract N.Sativa seed applied topically to staphylococcal-infected skin in mice improved healing by decreasing total and absolute WBC counts, local infection and inflammation, bacterial extension and impairment of tissue (Abu-Al-Basal, 2011). Using human gingival fibroblast as a monolayer, aqueous extract of N. Sativa displayed low free radical scavenging activity and caused proliferation of gingival fibroblasts with rapid wound closure activity despite its non-significant collagen synthesis impact. It also led in an increase in the basic fibroblast growth factor and a transformation of the growth factor beta. (Ab Rahman et al., 2014).

\section{Antiinflammatory Effect:}

In this randomized, double-blind, placebo-controlled clinical trial, forty-two patients with RA were allocated to two groups. Two capsules, $500 \mathrm{mg}$ each, of Nigella sativa oil were obtained by subjects in the intervention group for 8 weeks each day. For the same time period, the other group ate two capsules as placebo per day. At the baseline and end of the trial, serum TNF- $\alpha, I L-10$, and entire blood concentrations of oxidative stress parameters were evaluated. In the Nigella sativa group $(\mathrm{p}<0.01)$, the serum level of $\mathrm{IL}-10$ was increased. In addition, Nigella sativa therapy has resulted in a significant reduction in serum MDA and NO compared to baseline $(\mathrm{p}<0.05)$. There were no significant differences between or within the groups in the values of TNF- $\alpha$, SOD, catalase, and TAS before and after the intervention ( $p>0.05)$. This research shows that Nigella sativa in patients with rheumatoid arthritis (RA) could enhance inflammation and decrease oxidative stress. Nigella sativa is proposed as a useful adjunct treatment in this patient population.[22]

\section{Antiaging Effect:}

Aging is a gradual and unconscious method that can lead to modifications in biological systems. The aging process involves inducing oxidative stress and apoptosis, hepatotoxicity and neurotoxicity. Because of its antioxidant and anti-apoptosis characteristics it has been proven and assessed, black seed oil displayed an anti-aging impact in a D-galactose induced aging model. D-galactose administration (500 mg / kg, SC) enhanced serum concentrations of ALT and AST as well as MDA content in brain and liver tissue for 42 days, but reduced GSH content. In addition, apoptotic protein concentrations, including cleaved Bax, procaspase-3 and caspase-3, have risen significantly. N. Sativa oil ( 0.1 and $0.2 \mathrm{~mL} / \mathrm{kg}$ ) decreased concentrations of ALT and AST biochemical markers. Black seed oil administration $(0.1,0.2$ and $0.5 \mathrm{~mL} / \mathrm{kg}$ ) decreased lipid peroxidation and considerably restored GSH content at doses of 0.1 and $0.2 \mathrm{~mL} / \mathrm{kg}$. The oil reduced concentrations of Bax / Bcl2 and the expressions of caspase-3 (pro and cleaved) proteins in brain and liver tissues were downregulated at $0.1 \mathrm{~mL} / \mathrm{kg}$.[23]

\section{Anticancer Activity:}

TQ's antitumor and anti-angiogenicimpacts on in vitro and in vivo osteosarcoma have been explored. Results showed that in the human osteosarcoma cell line SaOS-2 TQ caused a greater proportion of growth inhibition and apoptosis relative to control, and TQ substantially blocked the development of human umbilical vein endothelial cell tube in a dose-dependent way. It was discovered that in SaOS-2 cells, TQ considerably reduced NF- $\pi$ B DNA-binding activity, XIAP, survivin, and VEGF. In addition, after therapy with TQ, the expression of cleaved caspase-3 and Smac was upregulated in SaOS- 2 cells. It has also been discovered that TQ inhibits angiogenesis of tumors and tumor development by suppressing NF- $\pi \mathrm{B}$ and its controlled molecules. It has been found that TQ efficiently inhibits in vitro and in vivo tumor development and angiogenesis. Inhibition of NF- $\mu \mathrm{B}$ and downstream effector molecules is therefore a possible underlying mechanism of TQ's antitumor and antiangiogenic activity in osteosarcoma. ${ }^{[24]}$ 


\section{Skin Cancer:}

N. sativa's anticancer activity was first disclosed when an increase in natural killer (NK) cell activity was reported in sophisticated cancer patients receiving multimodal immunotherapy program in which N. sativa seed was one of the components (El-Kadi and Kandil, 1986). Regarding dermatology, the antineoplastic effect of N.Sativa was first investigated by Salomi et al. (1991). They have reported topical application of N.Sativa and Crocus sativus extracts inhibited the two-stage initiation / promotion of [ dimethylbenz[a] anthracene (DMBA)/croton oil] induced skin cancer in mice, postponed the onset of papillomas and decreased the amount of papillomas per mouse in mice. Later, the protective influence of bee honey and nigella was subsequently researched in Sprague Dawely rats on the oxidative stress and carcinogenesis caused by methylnitrosourea (MNU). It was noted that in four out of six animals, MNU generated oxidative stress ranging from serious inflammatory reactions in the lung and skin to colon adenocarcinoma. There was also an increase in serum malondialdehyde (MDA) and nitric oxide (NO). Treatment with N. Sativa seed orally protected from MNU-induced oxidative stress and carcinogenesis $80 \%(12 / 15)$, while honey and N. Sativa seed together protected 100\% (12/12); and MDA and NO serum also reduced considerably in both instances compared with active monitoring. (Mabrouk et al., 2004).[25]

\section{Vitiligo:}

Extract of lyophilized seed from N. Sativa and its active ingredient, thymoquinone, showed substantial skin distortion on the isolated wall lizard melanophores (Ali and Meitei, 2011). When subjected to the extract or thymoquinone, the pigment cells reacted by separate melanin dispersion leading to skin obscuring. Anticholinergic drugs, atropine and hyoscine antagonized the melanin dispersal impact and potentiated by an anticholinesterase agent, neostigmine. The authors proposed that muscarinic cholinergic processes are actively involved in the dispersion of melanin (Ali and Meitei, 2011). Patients used N.Sativa oil in a randomized double blind clinical study, for vitiligo lesions twice daily for 6 months had a significant reduction in the scoring index of the vitiligo region with no substantial side effects.(Ghorbanibirgani et al., 2014).[26]

\section{Antidiabetic Effect:}

The therapeutic potential of $\alpha$-lipoic acid ( $\alpha$-LA), L-carnitine, and N. sativa or their mixture in carbohydrate and lipid metabolism was assessed in a diabetes Rat model caused by single i.p. streptozocin (STZ) injection of $65 \mathrm{mg} / \mathrm{kg}$. Fasting blood glucose, insulin, insulin sensitivity, HOMA, C-peptide, and pyruvate dehydrogenase activity have been determined for assessment of glucose metabolism. Both $\alpha$-LA and $\mathrm{N}$. Sativa decreased the amount of high blood glucose considerably. The mixture of 3 compounds considerably improved insulin and C-peptide levels. The combination of $\alpha$-LA, L-carnitine and $\mathrm{N}$. sativa will substantially lead to improving carbohydrate metabolism in diabetic rats, thereby improving the rate of progress in DM management.[27] The impacts of N. Sativa aqueous extract and oil, as well as TQ, have been researched in streptozotocin diabetic rats for serum insulin and glucose levels. Concentrations of serum insulin and glucose, SOD levels and malondialdehyde (MDA) pancreatic tissue have been determined. Any subcellular modifications were identified with electron microscopy. Diabetes enhanced concentrations of MDA tissue and serum glucose and reduced concentrations of insulin and SOD. Treatment of rats with N. Sativa extract and oil and TQ considerably reduced diabetes-induced increases in MDA and serum glucose tissue and considerably enhanced serum insulin and SOD tissue. Ultrastructurally, TQ improved most of the streptozotocin (STZ) poisonous impacts, including segregated nuclei, heterochromatin aggregates (showing harm to DNA), and mitochondrial vacuolization and fragmentation. The aqueous extract of N. Sativa also overturned, but to a smaller extent, these impacts of STZ. The N. Sativa oil restored ordinary levels of insulin but failed to lower to ordinary levels of serum glucose. The results of biochemistry and ultrastructure indicate that N. Sativa extract and TQ are therapeutic and safeguard against STZ diabetes by reducing oxidative stress, maintaining the integrity of pancreatic $\beta$-cells.

\section{Antioxytocic Activity:}

Some preliminary studies have recorded the N.Sativa antioxytocic characteristics. N. sativa seeds inhibit the uterine smooth muscle contraction caused by stimulation of oxytocin. The volatile oil N. Sativa seeds inhibited the spontaneous movement of the rat and guinea piguterine smooth muscle, as well as the oxytocin stimulation-induced contractions that suggest antioxytocin potential of N. Sativa's oil seeds.[28]

\section{Cosmetic Application:}

Using pH meter, corneometer, tewameter, methyl nicotinate micro-inflammatory model in human skin, and stratum corneum stripping tape, in vitro and ex vivo emulsion characteristics with seedcake extracts of N. Sativa was analysed(Amin et al., 2010). Emulsions with Borago officinalis, and N. Sativa seedcakes decreased skin irritation considerably and enhanced skin hydration and epidermal barrier function compared to placebo. Because of their antioxidant and anti-inflammatory operations, the authors proposed the prospective use of seed cakes in anti-aging, moisturizing, mitigating and protective cosmetics.

\section{Gastro-Protective Activity:}

Nigella sativa's gastric ulcer healing impact was research using 40 albino rats. Aspirin ( 0.2 gm / kg body weight) was provided to the animals to generate ulcers. Histopathology murdered four animals after 2 weeks to verify gastric ulcers. For the therapy with Nigella Sativa (30 mg / kg body weight) and Cimetidine (15 $\mathrm{mg} / \mathrm{kg}$ body weight), the remaining animals (36) were similarly split into two groups and the 3 subgroups according to the time timetable (2-6 weeks). At the end of the experimental period, rats were anesthetized and sacrificed and the stomachs removed, rinsed in lukewarm distilled water. To assess the outcomes, gross and microscopic examinations were carried out. On gross stomach examination, group "A" (taking Nigella Sativa) $14 / 18$ (78\%) albino snakes did not show any abnormality owing to total reaction to Nigella sativa compared to group "B" 17/18 (94\%) (taking Cimetidine). On microscopic examination of stomach, group "A" (taking Nigella Sativa) 13/18 (72\%) albino snakes disclosed full recovery compared to group "B" 16/18 (89\%) (taking Cimetidine). Therefore, the Nigella sativa is similarly efficient in healing gastric ulcer as is the use of $\mathrm{N}$-sativa in daily exercise in the treatment of gastric ulcer illness.[29]

\section{Cardiovascular Activity:}

The acute effects of diesel exhaust particles (DEP) on cardiopulmonary parameters in mice (at 4 and $18 \mathrm{~h}$ ) and TQ's protective effect have been investigated. Mice received either saline (control) or DEP (30 $\mu \mathrm{g}$ per mouse) intratracheally. Lung inflammation and loss of pulmonary 
function occurred at $18 \mathrm{~h}$ (but not $4 \mathrm{~h}$ ) after providing DEP. DEP induced systemic inflammation with leucocytosis at both 4 and $18 \mathrm{~h}$, enhanced levels ofIL-6, and decreased systolic blood pressure. SOD activity was only reduced at 6 p.m. DEP decreased the number of platelets in pial arterioles and aggravated in vivo thrombosis. In vitro, DEP $(0.1-1 \mu \mathrm{g} /$ $\mathrm{mL}$ ) is added to untreated platelet aggregation induced by the blood. Pretreatment of mice with TQ prevented declining systolic blood pressure and leucocytosis from DEP-induced, enhanced concentration of IL-6, and reduced activity of plasma SOD. TQ also stopped platelet numbers and prothrombotic occurrences from decreasing but not in vitro platelet aggregation. ${ }^{[30]}$

\section{Nephroprotective Activity:}

The protective effects of NSO have been investigated in the prevention of chronic cyclosporine A (CsA) -induced nephrotoxicity in rats. NSO significantly improved functional and histological parameters and diminished CsA-induced oxidative stress. NSO protects against oxygen-free radicals in the kidney tissue, preventing renal dysfunction and morphological defects associated with chronic CsA administration. [31] Administration of N. Sativa with GM intraperitonealinjection led in a significant reduction in creatinine, urea, MDA, NO generation and enhanced activity of SOD and GSH-Px relative to the nephro-protective activity of the GM group. N. Sativa functions as a powerful scavenger of free radicals in the kidney to avoid the toxic impacts of GM in both biochemical and histopathological parameters.[32] N. Sativa seeds had non-significant impacts on biochemical parameters of cisplatin-induced nephrotoxicity, although the histo-pathological characteristics of the kidneys recovered comparatively after N. sativa use.[33]

\section{Pulmonary-Protective Activity and Anti-Asthmatic Effects:}

The anti-asthmatic (bronchodilatory) effect of $\mathrm{N}$. sativa boiled extract in asthmatic patients ' airways was examined. In 15 asthmatic patients, bronchodilatory impacts of 50 and $100 \mathrm{mg} / \mathrm{kg}$ boiled extract were researched compared to 6 $\mathrm{mg} / \mathrm{kg}$ theophylline. PFTs including forced expiratory volume in one second, peak expiratory flow, maximal midexpiratory flow (MMEF), maximal expiratory flow at 75 percent, 50 percent and 25 percent FVC [ $\operatorname{MEF}(75), \operatorname{MEF}(50)$ and MEF(25) ] and particular airway conductance (sGaw) were analyzed prior to administration and repeated at 30 , $60,90,120,150$ and $180 \mathrm{~min}$ after oral extract administration. The results showed that the extract in most time intervals $(\mathrm{P}<0.05$ to $\mathrm{P}<0.001)$ caused a significant increase in all measured PFTs.[34]

\section{Hepato-Protective Activity:}

$\mathrm{N}$. sativa $(0.2 \mathrm{~mL} / \mathrm{kg})$ is reported to intraperitoneally relieve the deleterious impacts of liver injury caused by ischemia reperfusion. In hepatic tissue in rats with hepatic ischemia, biochemical parameters such as serum aspartate aminotransferase, alanine aminotransferase lactate dehydrogenase and total antioxidant capacity (TAC), CAT, total oxidative status (TOS), oxidative stress index (OSI) and MPO have been identified[86]. $N$. sativa administration protects hepatic tissue from harmful effects of toxic metals such as lead and reduces lipid peroxidation after exposure to chemicals such as carbon tetrachloride. Cadmium $(\mathrm{Cd}++)$ causes cell homeostasis alteration and oxidative damage. TQ's protective function in $\mathrm{Cd}++$ 's hepatotoxicity has been studied with unique regard to its protection against nonenzymatic and enzymatic antioxidant disruption. In postnuclear supernatant prepared from Swiss albino mice's liver under in vitro circumstances, the impact of TQ pretreatment was examined. Treatment with $\mathrm{CdCl} 2$ (5 mmol / L) led to a substantial rise in enzymatic antioxidant activity. It also induced a substantial rise in protein carbonyl $(\mathrm{P}<0.001)$ and decreased content of glutathione. TQ pretreatment $(10 \mu \mathrm{mol}$ / L) showed important protection as shown by noticed protein oxidation attenuation and rejuvenation of cell fraction depleted antioxidants. These findings reinforce the hypothesis that on being subjected to toxic insult, TQ exerts modulatory impact on the antioxidant protection mechanism. [35]

\section{CONCLUSION:}

Nigella Sativa is widely referred to as black seed. Its seeds and oil have been widely used in the treatment of various diseases worldwide. In this review, Cultivation and collection,chemical composition and pharmacological activity of Nigella Sativa is been shown. Different pharmacological activities such as antibacterial, antiviral, antifungal activity, hair loss, antioxidant property, preservative property, sun protection, wound healing activity, antiinflammatory activity, antiaging activity, anticancer activity, skin pigmentation, antidiabetic activity, antioxytocic activity, cosmetic application, gastro-protective activity, cardiovascular activity, nephroprotective activity, pulmonary-protective activity and anti-asthmatic activity and hepato-protective activity.

\section{REFERENCES:}

1. Khare CP. Encyclopedia of Indian medicinal plants. NewYork: Springes-Verlag Berlin Heidelberg; 2004.

2. Sharma PC, Yelne MB, Dennis TJ. Database on medicinal plants used in Ayurveda. New Delhi: 2005. pp. 420-440.

3. Goreja WG. Black seed: nature's miracle remedy. New York, NY: Amazing Herbs Press; 2003.

4. Al-Bukhari MI. In: The collection of authentic sayings of prophet mohammad (peace be upon him), division 71 on medicine. 2nd ed. Al-Bukhari Sahi., editor. Ankara: Hilal Yayinlari; 1976.

5. Abel-Salam BK. Immunomodulatory effects of black seeds and garlic on alloxan-induced diabetes in albino rat. Allergol Immunopathol (Madr) 2012; 40(6):336-340. [PubMed]

6. Al-Ali A, Alkhawajah AA, Randhawa MA, Shaikh NA. Oral and intraperitoneal $\mathrm{LD}_{50}$ of thymoquinone, an active principle of Nigella sativa, in mice and rats. J Ayub Med Coll Abbottabad. 2008; 20(2):25-27. [PubMed]

7. saha rajsekher, bhupendar kuldeep :pharmacognosy and pharmacology of nigella sativa. 2011;36-39

8. Sudhir P, Deshmukh VO and VeRMA HN: International Journal of Pharmaceutical Sciences And Research, 2016; 7(8):3185.

9. Al-Jassir MS. Chemical composition and microflora of black cumin (Nigella sativa L.) seeds growing in Saudi Arabia. Food Chem 1992; 45: 239-242.

10. Atta-Ur-Rahman. Nigellidine-a new indazole alkaloid from the seed of Nigella sativa. Tetrahedron Lett 1995; 36(12): 19931994.

11. Nickavar B, Mojab F, Javidnia K, Amoli MA. Chemical composition of the fixed and volatile oils of Nigella sativa $L$. from Iran. Z Naturforsch C 2003; 58(9-10):629-631

12. M.S.M Hanafi ,M.E .Hateem : Studies on the antimicrobial activity of Nigella sativa seed (black cumin) 1991; 34(23):275-278.

13. Mohamed Shohayeb and Eman Halawani : Comparative Antimicrobial Activity of Some Active Constituents of N. sativa L ,2012; 20(2):182-189.

14. Zaoui, Y. Cherrah, N. Mahassini, K. Alaoui, H. Amarouch, M. Hassar, Acute and chronic toxicity of Nigella sativa fixed oil, 
Phytomedicine, Volume 9, Issue 1, 2002, Pages 69-74, ISSN 0944-7113, ttp://dx.doi.org/ 10.1078/0944-7113-00084.

15. Robert W. Lebling \& Donna Pepperdine MH.Natural Remedies of Arabia. Stacey International. ISBN: 1-905299-02-8 2006 ; Page 30.

16. Alfredo Rossi, Lara Priolo, Alessandra Iorio, Enrica Vescarelli, Martina Gerardi, Daniele Campo, Donato Di Nunno, Simona Ceccarelli, Stefano Calvieri, Antonio Angeloni, Cinzia Marchese Evaluation of a Therapeutic Alternative for Telogen Effluvium: A Pilot Study, Journal of Cosmetics, Dermatological Sciences and Applications, 2013; 3:916 http://dx.doi.org/10.4236/jcdsa.2013.

17. Shahinoor Rahaman Dulal, Hasib Sheikh, Mohammad Abu Taher, Mohammad Sayeed Ur Rahaman, Zakia Rahman and M.A. Malek, Formulation and finding out the efficacy of the herbal hair oil over simple coconut oil (Purified) - A formulation and clinical study in Bangladesh, International Journal of Pharmaceutical Sciences and Research , 2014; 5(5):1801-1805.

18. Burits and F. Bucar, Antioxidant activity of Nigella sativa essential oil Published online: 28 JUL 2000, DOI: 10.1002/1099-1573(200008)14:5<323: AID-PTR621> 3.0. C0;2-QPhytotherapy Research 2000; 14(5):323-328.

19. H. Al. Bahtiti , Chemical Investigation and Preservative Effect of Jordanian Nigella sativa L. Seed Oil on Date Paste , International Journal of Research Studies in Biosciences (IJRSB)Volume 2015; 3(4):1-5

20. Alsawaf and H. S. Alnaemi Effect of Nigella sativa (seed and oil) on the bacteriological quality of soft white cheese Iraqi Journal of Veterinary Sciences, 2011; 25(1):21-27.

21. Shantanu Kale, Prashant Ghoge, Ammar Ansari, Ashwini Waje, Amol Sonawane. Formulation and in-vitro determination of Sun Protection Factor of Nigella sativa Seed Oil Sunscreen Cream. 2010; 2(4):194-2197.

22. Vahid Hadi ,Sorayya Kheirouri, Mohammad Alizadeh,Alireza Khabbazi and Hossein Hosseini: Effects of Nigella sativa oil extract on inflammatory cytokine response and oxidative stress status in patients with rheumatoid arthritis: a randomized, double-blind, placebo-controlled clinical trial:2016; 6(1): 34-43.

23. Salama RH. Hypoglycemic effect of lipoic acid, carnitine and Nigella sativa in diabetic rat model. Int J Health Sci (Qassim) 2011; 5(2): 126-134.
24. Peng L, Liu A, Shen Y, Xu HZ, Yang SZ, Ying XZ, et al. Antitumor and anti-angiogenesis effects of thymoquinone on osteosarcoma through the NF-kB pathway. Oncol Rep 2013; 29(2): 571-578.

25. El-Kadi, A., Kandil, O.,. Effect of Nigella sativa (the black seed) on immunity. In: Proceedings of the Fourth International Conference on Islamic Medicine, 4 Novembr, Kuwait, 1986; pp. 344-348

26. Ali, S.A., Meitei, K.V., Nigella sativa seed extract and its bioactive compound thymoquinone: the new melanogens causing hyperpigmentation in the wall lizard melanophores. J. Pharm. Pharmacol. 2011; 63(5):741-746.

27. Salama RH. Hypoglycemic effect of lipoic acid, carnitine and Nigella sativa in diabetic rat model. Int J Health Sci (Qassim) 2011; 5(2): 126-134.

28. Aqel M,Shaheen R. Effects of the volatile oil of Nigella sativa seeds on the uterine smooth muscle of rat and guinea pig. J Ethnopharm 1996; 52(1): 23-26.

29. javed khalil, shahnaz akhter, shabir a. Bhatti and m. $\mathrm{H}$. Bukhari: Biomedical; 2010; 26:61-65

30. Nemmar A, Al-Salam S, Zia S, Marzouqi F, Al-Dhaheri A, Subramaniyan D, et al. Contrasting actions of diesel exhaust particles on the pulmonary and cardiovascular systems and the effects of thymoquinone. Br J Pharmacol 2011; 164(7): 1871-1882

31. Uz E, Bayrak O, Uz E, Kaya A, Bayrak R, Uz B, et al. Nigella sativa oil for prevention of chronic cyclosporine nephrotoxicity:an experimental model. Am J Nephrol 2008; 28(3): 517-522.

32. Yaman I, Balikci E. Protective effects of Nigella sativa against gentamicin-induced nephrotoxicity in rats. Exp Toxicol Pathol 2010; 62(2): 183-190.

33. Hadjzadeh MA, Keshavarzi Z, Yazdi TSA, Ghasem SM, Rajaei Z, Khajavi Rad A. Effect of alcoholic extract of Nigella sativa on cisplatin-induced toxicity in rat. Iran J Kidney Dis 2012; 6(2):99- 104

34. Boskabady MH, Mohsenpoor N, Takaloo L. Antiasthmatic effect of Nigella sativa in airways of asthmatic patients. Phytomedicine 2010; 17(10):707-713.

35. Zafeer MF, Waseem M, Chaudhary S, Parvez S. Cadmiuminduced hepatotoxicity and its abrogation by thymoquinone. J Biochem Mol Toxicol 2012; 26(5):199-205. 